\title{
Histopathology of cotton bollworm midgut infected with Helicoverpa armigera cytoplasmic polyhedrosis virus
}

\author{
Rasoul Marzban ${ }^{1,2}$,Qian $\mathrm{He}^{2}$, Qingwen Zhang ${ }^{2}$, Xiao Xia Liu ${ }^{2}$ \\ ${ }^{1}$ Department of Biological Control, Iranian Research Institute of Plant Protection, Tehran, Iran. \\ ${ }^{2}$ Department of Entomology, College of Agronomy and Biotechnology, China Agricultural University, \\ Beijing, China.
}

Submitted: July 3, 2012; Approved: April 4, 2013.

\begin{abstract}
This research was carried out to examine cytopathological effects of Helicoverpa armigera Cytoplasmic polyhedrosis virus (HaCPV) on infected midgut cotton bollworm (Helicoverpa armigera) using transmission and scanning electron microscope. The symptoms on infected host larvae of the host, compared with healthy ones, were getting swollen with milky-white and fragile Histopathological examinations showed infection with HaCPV small polyhedral inclusion bodies (PIB) after 1 or 2 days which were observed in columnar cells of midgut. Virions were partially or completely occupied in a polyhedral matrix to form polyhedral inclusion bodies (PIB) at periphery of virogenic stroma. PIBs were measured 0.5 to $3.5 \mu \mathrm{m}$ and virions about $46 \mathrm{~nm}$ in diameter. Microvilli of infected columnar cells were affected and degenerated immediately prior to rupture of the cell. Some infected columnar cells ruptured to release PIB into the gut lumen 3 days after infection. In addition,PIB were found in goblet cells, 5 or 6 days after infection. Infected goblet cells degenerate to such an extent that only a few of the original microvillus-like cytoplasmic projections and cell organells were left. These cytopathic effects caused in the midgut by HaCPV on cotton bollworm larvae are essentially similar to those have been reported for lepidoperan and dipteran infection by CPV.
\end{abstract}

Key words: cytoplasmic polyhedrosis virus, Helicoverpa armigera, histopathology, HaCPV.

\section{Introduction}

Most insect reoviruses described to date belong to the family Reoviridae within the genus Cypovirus (Cytoplasmic polyhedrosis virus- $\mathrm{CPV}$ ). These viruses have been reported as pathogens of the midgut epithelium in numerous lepidopteran and dipteran species, because these insects are, respectively, of economic or medical importance (Mertens et al., 2004). CPVs are so-named because they produce large polyhedral occlusion bodies that occlude virions in the cytoplasm of infected cells. They have been recognized as an important entomopathogen, especially among lepidopteran insects because of their potential for biological control (Martignoni and Iwai, 1981). CPVs infect midgut cells of a wide range of insects (Payne and Rivers, 1976). Inclusion bodies after ingestion by insects, dissolve and break, and release infectious virions which enter and repli- cate in the cytoplasm of midgut epithelial cells (Mertens et al., 1999, 2004). Infection is usually limited to the insect gut wall. Infection frequently results in death or loss of fitness of the host which is reported to be important in regulating host populations (Dwyer et al., 2004). Most CPV infections produce chronic disease with low mortality, although some are pathogenic (Mertens et al., 1999, 2004). Helicoverpa armigera Cytoplasmic polyhedrosis virus (HaCPV) (Chinese strain) is a mixture of CPV, so that Belloncik et al. (1996) using cell culture, separated type 14., Li et al. (2006) separated type 5 from a mixture of HaCPVs. They reported that $\mathrm{HaCPV}$ is virulent to $H$. armigera and has the potential to be used as a bioinsecticide. HaCPV had negative impact on growth and development of $H$. armigera, and resulted in reduced pupation and pupal weight and an extended developmental period, especially in early instars larvae (Marzban et al., 2009). HaCPV 
Sub lethal effects may be due to the diversion of host energy to support or combat the pathogen (Marzban, 2012; Sikorowski and Thampson, 1979; Wiygul, and Sikorowski, 1978, 1991). H. armigera is one of the most serious insect pests of cotton, corn, vegetables, and other crops in the Old World including Iran. It has a history of developing resistance to almost all of the insecticides used for its control. Transgenic cotton incorporating Cry $1 \mathrm{Ac}$ gene derived from Bacillus thuringiensis Berliner is one of the most exciting advances made in cotton pest management in recent years. Resistance monitoring of $H$. armigera field populations suggested that there has been some decline in the susceptibility to Cry1Ac in the field (Gunninget al., 2001; Lietal., 2004; Shenet al., 1998). Therefore, alternative control measures, such as biological control agents, are required. $\mathrm{HaCPV}$ is a highly infectious insect pathogen (Lietal., 2006; Martignoni and Iwai, 1981) and a candidate for biocontrol of $H$. armigera, especially in combination with B. thuringiensis toxins (Iwashita, 1971; Kawase and Miyajima, 1971; Katagiri et al., 1978; Ying, 1986). Presently there is no description of the histopathology of HaCPV on cotton bollworm, $H$. armigera. This study was undertaken to examine the pathological effects of $\mathrm{HaCPV}$ on the midgut of cotton bollworm, which forms part of the groundwork for evaluation of $\mathrm{HaCPV}$ potential in the integrated control of this pest, for dealing with the decline in the susceptibility of cotton bollworm to Cry1Ac toxin.

\section{Materials and Methods}

\section{Insect}

$H$. armigera used in this study obtained from the Wang Mo laboratory, Hua Zhong Agricultural University, Wuhan. For eliminating surface contaminations, the eggs, of each generation, were disinfected by immersing in $2 \%$ formaldehyde for $15 \mathrm{~min}$ at room temperature, then washed several times with tap water and finally rinsed with sterile distilled water. The eggs were allowed to air-dry on tissue paper and left to hatch in $10 \times 6 \mathrm{~cm}$ plastic bags at $26^{\circ} \mathrm{C}$ .The larvae were individually fed artificial diet at $26^{\circ} \mathrm{C}$ and $65 \% \mathrm{RH}$, with a $14: 10 \mathrm{~h}$ photoperiod (Bot, 1966). Adults were fed with a diet sweetened with $10 \%$ honey solution.

\section{Preparation and purification}

HaCPV was provided by Dr Jiang Zhong (Fudan University, Shanghai) that it is a mixture type CPV. H. armigera larvae were reared on an artificial diet. The eggs were disinfected, air-dried and incubated as described above.The larvae and adults, also, were fed same as explained above.

The first-instar larvae were infected with HaCPV by spraying a suspension of $3 \times 10^{7}$ polyhedra on the artificial diet and allowed to feed normal artificial diet until newly moulted second-instar (3 day old) larvae. On day 7 after infection, midguts were homogenized in deionized water and strained through $35-\mu \mathrm{m}$ mesh nylon cloth to remove large debris. The filtrated product was layered on top of HS-40 Ludox continues gradient and centrifuged at $16000 \mathrm{~g}$ for $45 \mathrm{~min}$. The resulting band containing purified virus was recovered, washed in sterile distilled water three times and maintained in $0.1 \mathrm{mM} \mathrm{NaOH}$ at $5{ }^{\circ} \mathrm{C}$.

\section{Treatment}

$H$. armigera larvae were placed individually in glass diet tubes $(1 \times 6 \mathrm{~cm})$ containing a $1-\mathrm{cm}$ diameter cotton leaf discs on moist sterile tissue paper. The discs were disinfected with $0.5 \%$ sodium hypochlorite for $10 \mathrm{~min}$ and immediately washed three times in sterile water. The discs were treated with $5 \mu \mathrm{L}$ of viral suspension $\left(3 \times 10^{7}\right.$ polyhedra) with a micropipette prior to adding larvae. Control larvae were fed leaf discs treated with sterile distilled water. Those larvae that consumed whole leaf disc were used for electron microscopy studies.

\section{Electron microscopy}

Foregut, midgut, hindgut, abdominal lipids, and malpighian tubules of the larvae were dissected at 1,2,3,4, 5 or 6 days after treatment. For transmission electron microscopy (TEM), tissues were fixed in $2.5 \%$ glutaraldehyde, washed with PBS and postfixed in cold, buffered, $1 \%$ osmium tetroxide, dehydrated in an ethanol series, infiltrated and embedded in Spurr's resin. Ultrathin sections were obtained with a Leica UC6 ultramicrotome equipped with glass knives, and stained with $0.5 \%$ ethanolic uranyl acetate and lead citrate, and examined using a JEM-123O TEM at $80 \mathrm{kV}$. For scanning electron microscopy (SEM), tissues were fixed overnight in $2.5 \%$ glutaraldehyde, washed as before, dehydrated in an ethanol series, isoamyl acetate for substitution and dried by critical point drying method. Dried tissues were mounted, coated with gold-palladium, and examined using a Hitachi HH-3400 SEM at $30 \mathrm{kV}$.

\section{Results}

\section{Symptomology}

Virus infection noticeably affects the development, feeding, or behavior of the infected larvae. After about $48 \mathrm{~h}$ post infection, the larvae become sluggish, move little, and cease to feed. After 3-4 days, the larvae midgut becomes hypertrophied and overgrown with milky-white aspect and fragile (Figures 1 and 2). After about 7 days the larvae die, the body contents liquefies and the skin remained intact without marked change in color as in nuclear polyhedrosis infection.

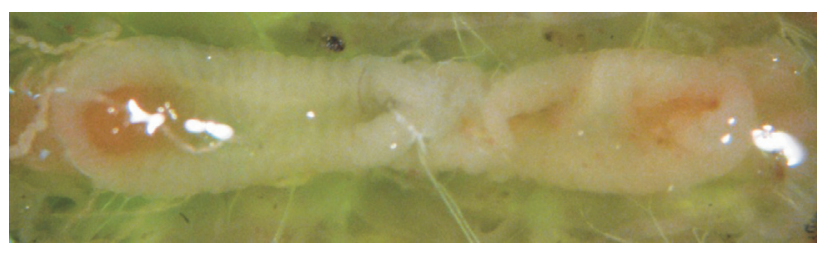

Figure 1 - Gut of healthy larvae of Helicoverpa armigera. 


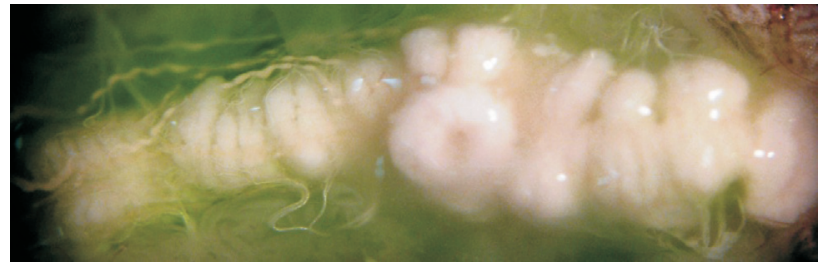

Figure 2 - Gut of HaCPV-infected larvae of Helicoverpa armigera.

\section{Histopathology}

Examination of larval gut tissues by electron microscopy revealed viral infection in the cytoplasm of foregut, midgut, and hindgut. There was no evidence of virus particles or polyhedra in the nuclei. Viral particles were localized in regions of the cytoplasm that were tightly packed with inclusion bodies and lacked typical cytoplasmic organelles. In some of the epithelial cells of midgut, these cypovirus areas occupied more than two-thirds of the cytoplasm, although other regions of even heavily infected cells looked unchanged, containing all of the normal cellular organelles. No ultrastructural changes and no polyhedral inclusion body (PIB) were observed in the Malpighian tubules. In contrast, fat bodies of infected larvae contained large number of HaCPV particles. For this publication, the results of midgut infection are presented.

The midgut epithelium of cotton bollworm larvae consists of three types of cells: columnar and goblet cells, which make up most of the midgut epithelium, and the basal regenerative cells (Figure 3). Small PIB $(<1 \mu \mathrm{m})$

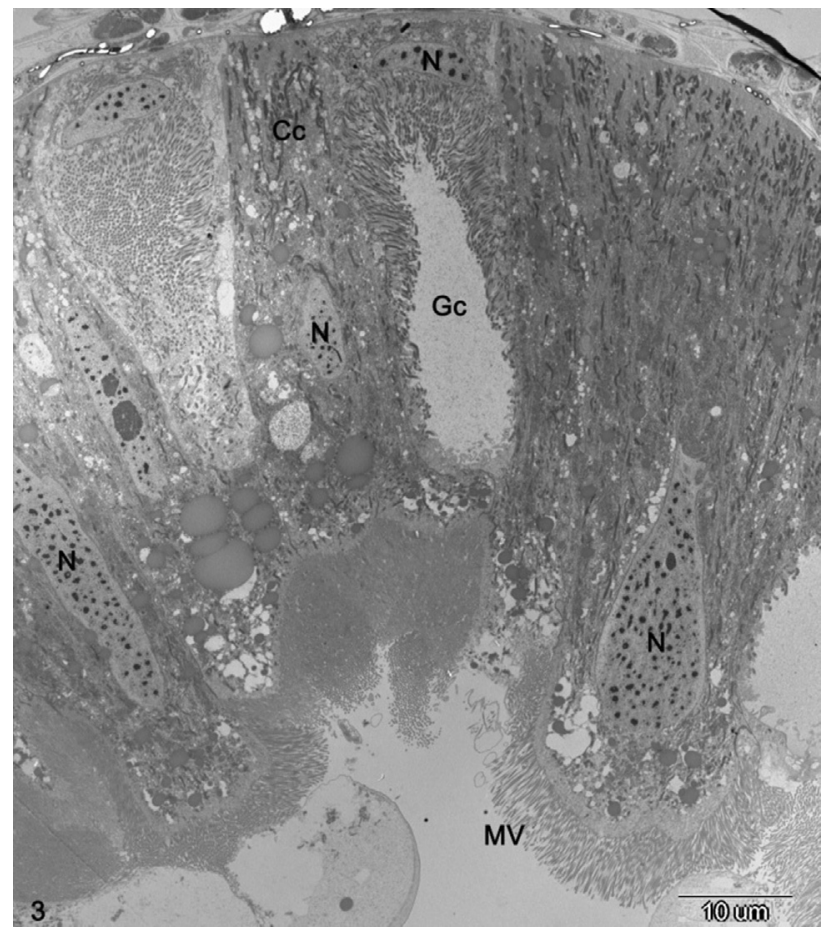

Figure 3 - Surface of midgut epithelium of a normal cotton bollworm larva, showing distinct nucleus $(\mathrm{N})$, microvilli (Mv), columnar cells $(\mathrm{Cc})$, and goblet cell $(\mathrm{Gc})$. were observed in some of the columnar cells 1 or 2 days after treatment with HaCPV. The PIBs sizes were 0.5 to $3.5 \mu \mathrm{m}$. The diameter of virions measures from 41 to $51 \mathrm{~nm}$, with a mean of $46 \mathrm{~nm}$.

On day 3 after infection, infected columnar cells were packed with PIB that virtually fill the whole cell (Figure 4). At this stage of infection the microvilli, which cover the apical ends of columnar cells, were not affected. However, at more advanced stages of infection and just prior to cell rupture, the apical microvilli deteriorated, revealing the bare and distended apices of infected cells (Figure 5). The distended cells eventually ruptured through their apices, releasing PIB into the gut lumen (Figure 6).

On day 4 after infection, deterioration of mitochondria and rough endoplasmic reticulum were observed (not shown). The mitochondria became swollen and eventually disintegrated. There is little or no rough endoplasmic reticulum within infected cells (not shown). At this stage, the nucleus in many of the infected columnar cells was still present (not shown). Examinations of sectioned tissues with the electron microscopes showed that infections occurred in the cells of the fat body. Because adjacent cells usually differed in the degree and stage of infection, the virus in cells in earlier stages of infection varied in size; those in terminally infected cells were uniformly large, an indication that individual virus grow during the infection. On day 5 or 6 after treatment, PIB were observed in some goblet cells (Figure 7). The process of infection of goblet cells is similar to that described for columnar cells. Infected goblet cells degenerate to such an extent that only a few of the original microvillus-like cytoplasmic projections and cell organelles were presented, as compared with control (Figures 7,8$)$.

\section{Discussion}

The midgut epithelium is mainly involved in the absorption of nutrients and other useful substances and their transport. In addition, it has an important role in the removal of unwanted and harmful substances from the body.

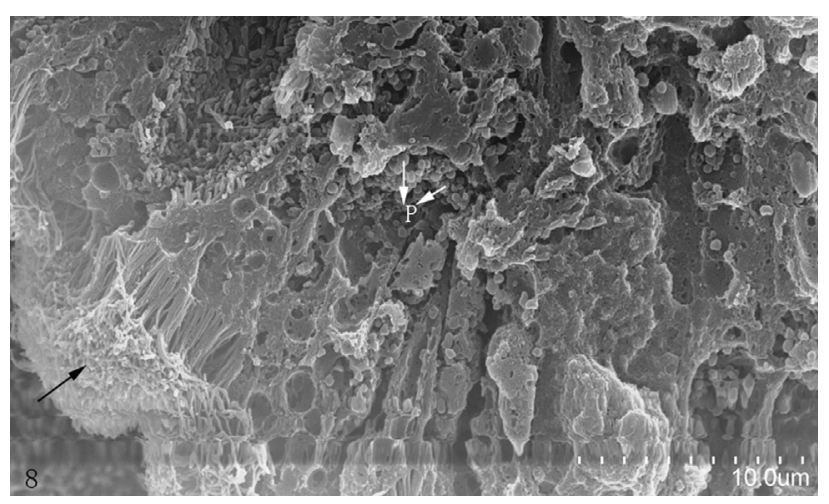

Figure 4 - SEM micrograph of a cryofracture surface near apex of heavily infected columnar cell, showing enormous number of PIB (P) that almost fills the columnar cells and the unaffected microvilli (arrow). 


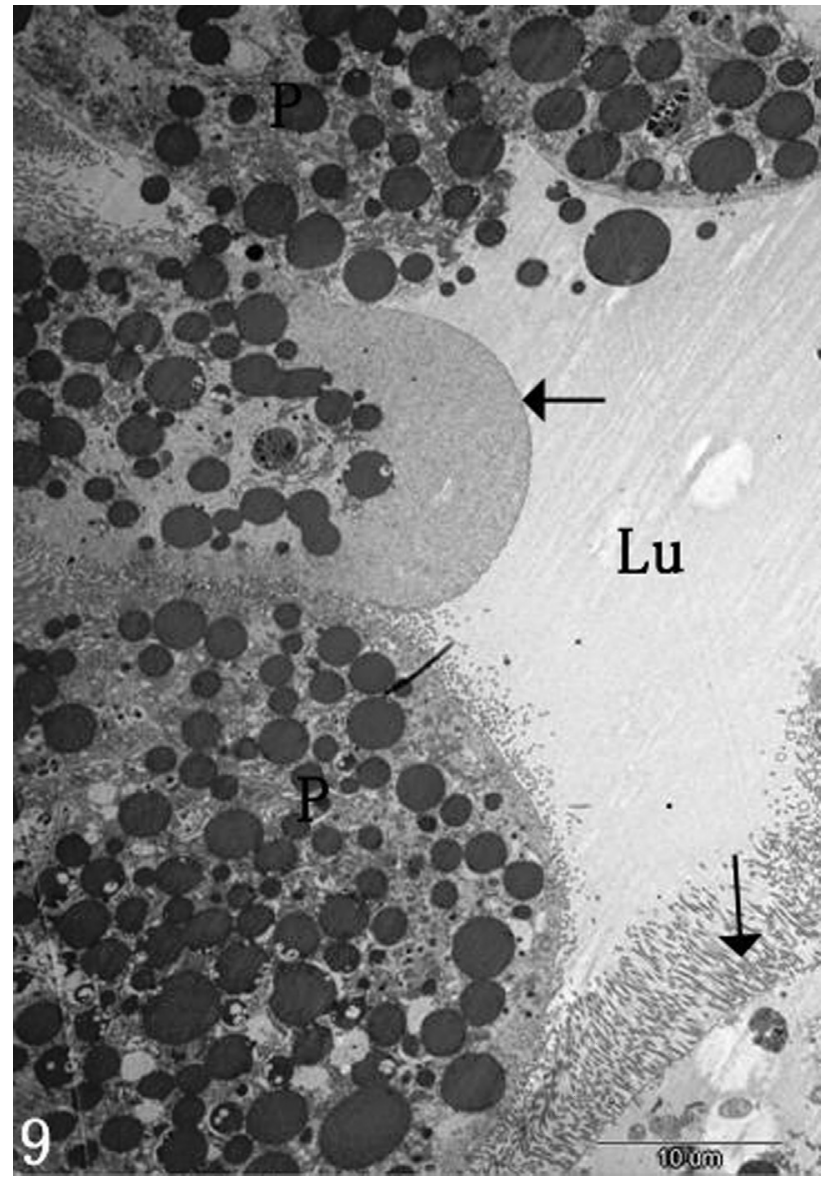

Figure 5 - HaCPV-Infected midgut lining of Helicoverpa armigera, showing the bare apices (arrow) of heavily infected columnar cells immediately prior to rupture. Note the large number of polyhedra inclusion bodies $(\mathrm{P})$.

The histopathology of HaCPV in the midgut of the cotton bollworm was similar to that of reported for the corn earworm (Bong and Sikorowski, 1991) and the silkworm (Iwashita, 1971; Kawase and Miyajima, 1971) infected with cypoviruses, especially regarding to changes in the columnar cells. Small PIB were found in some midgut columnar cells of the cotton bollworm as early as one day after treatment. Penetration of the Cytoplasmic polyhedrosis virus particles into the cotton bollworm midgut incidented much earlier. In the silkworm, penetration of the virus particles into midgut cells occurs within 10 min of inoculation (Kobayashi, 1971) and small PIB are observed in the midgut cells $48 \mathrm{~h}$ later (Kawase and Miyajima, 1971). Apparently, formation of PIB is more rapid in the cotton bollworm than that in the silkworm.

The PIB in cotton bollworm are in general smaller (0.5 to $3.5 \mu \mathrm{m})$ than those reported for silkworm and other lepidopterous insects (Aizawa, 1971; Cunninghamand longworth, 1968), the PIB as large as $5 \mu \mathrm{m}$ occur in larvae of the monarch butterfly, Danaus plexippus (L.) (Arnott et al., 1968). The virion $(46 \mathrm{~nm})$ in the cotton bollworm is

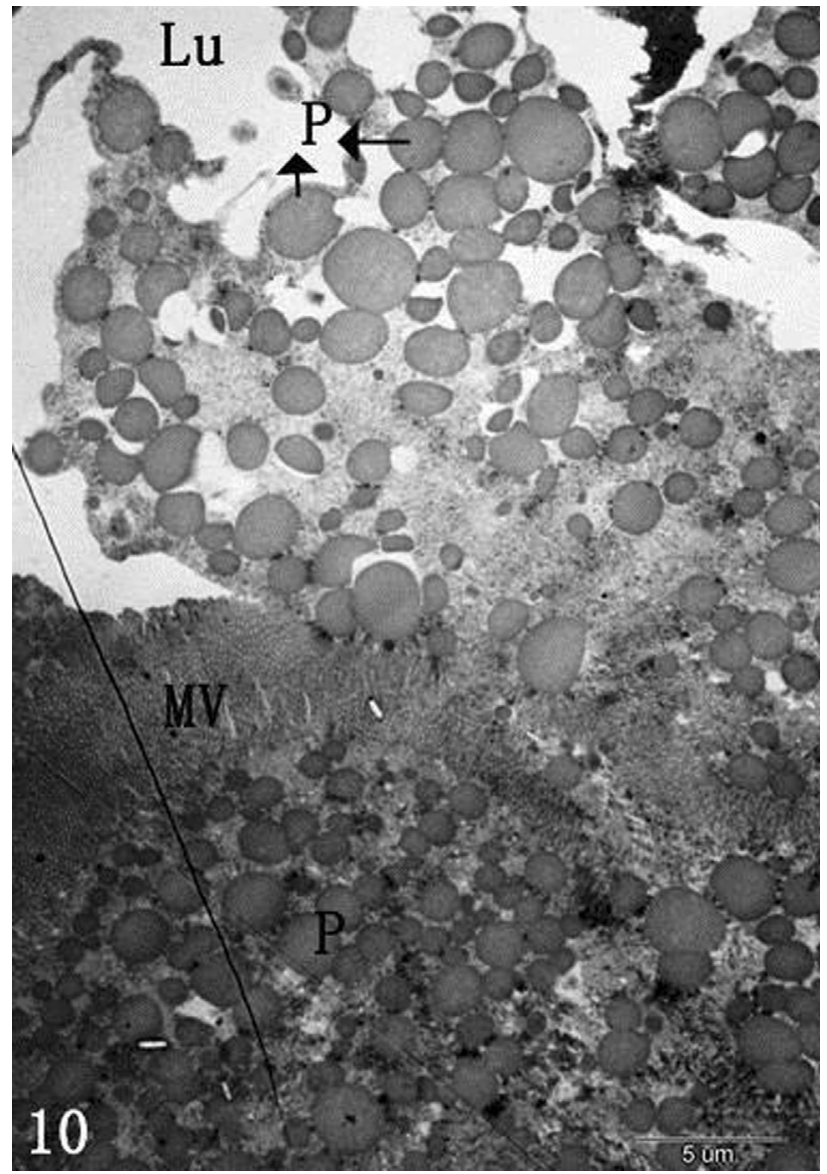

Figure 6 - Infectd midgut lining, showing the bare apices of ruptured columnar cells releasing PIB (P) into the lumen (Lu).

smaller than the general size range $(60-80 \mathrm{~nm})$ reported for CPV (Fenner, 1976). The virion measures $69 \mathrm{~nm}$ in the silkworm (Aizawa, 1971)and $67 \mathrm{~nm}$ in monarch butterfly larvae (Arnott et al., 1968).

Kobayashi (Kobayashi, 1971) showed that the virogenic stroma is the developmental focus of viral synthesis where formation of PIB takes place. Formation of HaCPV PIB in the cotton bollworm is similar to that in the silkworm that infected with CPV. Empty capsids described by Arnott et al. (1968) in larvae of the monarch butterfly which infected with CPV are not observed in the cotton bollworm. In infected columnar cells, the microvilli, which play a vital role as the absorptive lining of the gut lumen, are severely affected. Whereas, microvilli of infected columnar cells are partially or completely absent and they contain large number of PIB. This differs from that reported for the corn earworm, Helicoverpa zea (Boddie) that infected with $\mathrm{CPV}$ (Bong and Sikorowski, 1991).

Most digestive and adsorptive functions of the insect occur in the midgut. So, its damage by HaCPV would adversely affect the normal growth and development of cotton bollworm. Marzban et al. (2009) found that exposure of $H$. armigera larvae to $\mathrm{HaCPV}$ have negative impact on its 


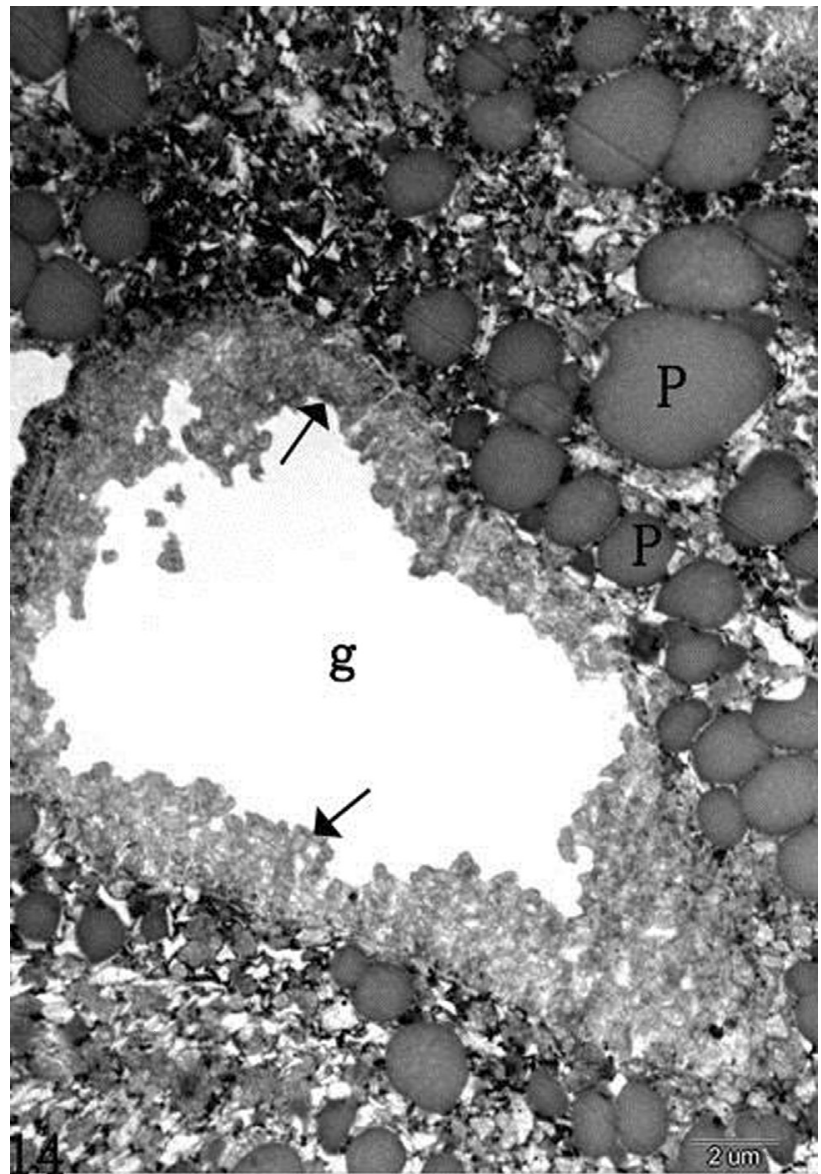

Figure 7 - HaCPV-infected goblet cell of Helicoverpa armigera, showing numerous PIB (P). Mitochondria and rough endoplasmic reticulum are absent in the cell, and degenerated microvilli (arrow). Goblet chamber (g).

growth and development which resulted in reducing pupation and pupal weight and an extended developmental period. Also, viral synthesis requires energy. The large number of PIB within infected cells indicates a great expenditure of the insect's metabolic energy. Marzban (2012) observed that HaCPV-infected cotton bollworm reduced significantly not only body weight of larvae, but also glycogen, soluble protein, and total lipid content. This is indicative of extensive diversion of normal metabolism for synthesis of viral materials adversely affecting normal functions of the insect.

As infection advances, columnar cells becomes filled with PIB, and so distended that they rupture through their apices releasing PIB into the gut lumen.

Infected columnar cells of the cotton bollworm exhibit additional changes. The mitochondria and rough endoplasmic reticulum degenerate 3 or 4 days after the onset of infection. Kobayashi (Kobayashi, 1971) reported similar observations for rough endoplasmic reticulum in CPV-infected silkworm midgut, but found that mitochondria remained normal except for several enlarged ones near the virogenic stroma. In advanced stages of infection, the nuclei of infected cells are obscured by the large number of PIB.

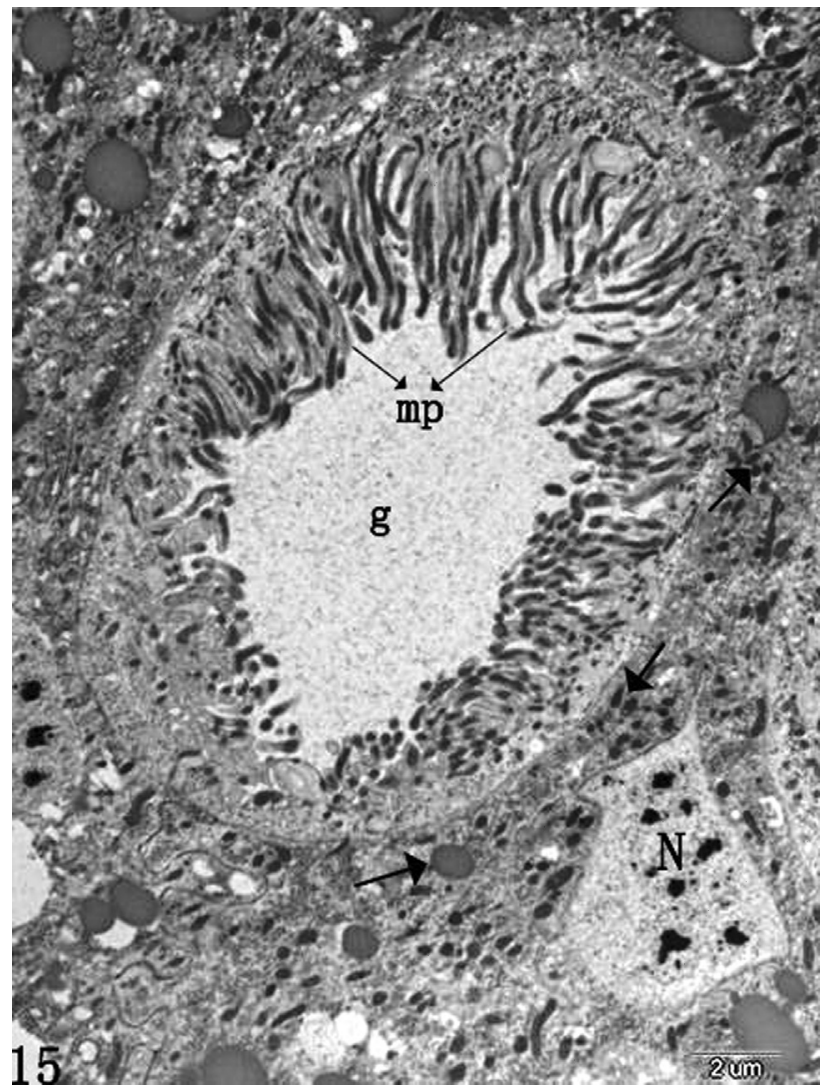

Figure 8 - Goblet cell of uninfected $H$. armigera larva, showing basal nucleus $(\mathrm{N})$, numerous mitochondria (arrow),), microvillus-like cytoplasmic projections (mp), and goblet chamber (g).

Goblet cells are infected by HaCPV 5 or 6 days after treatment and undergo serious changes leading them to deterioration. Goblet cells are responsible for potassium ion transport from heamolymph to the gut lumen (Aizawa, 1971). These histopathological data is part of researches evaluating the potential of $\mathrm{HaCPV}$ as a biocontrol agent in the integrated pest management of the cotton bollworm.

\section{Acknowledgments}

The authors are grateful to Dr. M. motazeri of Iranian Research Institute of Plant Protection and two anonymous reviewers for their critical review and comments on the manuscript. We are indebted to Dr Jiang Zhong (Fudan University) who most generously provided cytoplasmic polyhedrosis virus of $H$. armigera for this study; also extend our appreciation to Dr Wang Mo (Hua Zhong agricultural University) for providing $H$. armigera pupae. This research was funded by "973" Projects (2006CB100204) and the State Key Research Programs of Science and Technology Ministry (2006BAD08A07-05) of PR China.

\section{References}

Aizawa K (1971) Structure of polyhedra and viral particles of cytoplasmic polyhedrosis. In: Aruga, H., Tanada, Y. (eds). The 
cytoplasmic polyhedrosis virus of the silkworm. Tokyo, p. 23-59.

Anderson E, Harvey WR (1966) Active transport by the cecropia midgut. Fine structure of the midgut epithelium. J Cell Biol 31:134-160.

Arnott HJ, Smith KM, Fullilove SL (1968) Ultrastructure of a cytoplasmic polyhedrosis virus affecting the monarch butterfly, Danaus plexippus. Development of virus and normal polyhedra in the larva. J Ultra Mol Struct R 24:479-507.

Bong CFJ, Sikorowski PP (1991) Histopathology of Cytoplasmic polyhedrosis virus (Reoviridae) infection in corn earworm Helicoverpa zea (Boddie) larvae (Insecta: Lepidoptera: Noctuidae). Can J Zool 69:2121-2127.

Bot J (1966) Rearing Helicoverpa armigera (Hubner) and Prodenia litura F. on an artificial diet. J Agric Sci 9:538539.

Cunningham JC, longworth JF (1968) The identification of some cytoplasmic polyhedrosis viruses. J Invertebr Pathol 11:196-202.

Dwyer G, Dushoff J, Yee SH (2004) The combined effects of pathogens and predators on insect outbreaks. Nature 430:341-345.

Fenner F (1976) The classification and nomenclature of virus. Intervirology 7:1-115.

Flower NE, Filshie BK (1976) Goblet cell membrane differentiation in the midgut of a lepidopteran larva. J Cell Sci 20:357375.

Gunning R, Dang H, Christiansen I (2001) Play your part in resistance testing. Australian Cotton Grower 22:18.

Iwashita Y (1971) Histopathology of cytoplasmic polyhedrosis virus of the silkworm. In: Aruga, H., Tanada, Y. (eds). The cytoplasmic polyhedrosis virus of the silkworm. Tokyo, p. 23-59.

Katagiri K (1981) Pest control by cytoplasmic polyhedrosis viruses, pp.433-440. In: H. D. Burges (ed.). Microbial control of pests and plant diseases 1970-1980. Academic Press, New York.

Katagiri K, Iwata Z (1976) Control of Dendrolimus spectabilis with a mixture of cytoplasmic polyhedrosis virus and Bacillus thuringiensis.Appl Entomol Zool 11:363-364.

Katagiri K, Iwata Z, Kushida T, Fukuizumi Y, Ishizuka H (1977) Effects of application of $B t, \mathrm{HACPV}$ and a mixture of $B t$ and HACPV on the survival rates in populations of the pine caterpillar, Dendrolimus spectabilis. J Jpn Fore Soc 59:442448.

Katagiri K, Iwata Z, Ochi K, Kobayashi F (1978) Aerial application of a mixture of CPV and Bacillus thuringiensis for the control of the pine caterpillar, Dendrolimus spectabilis. J Jpn Fore Soc 60:94-99.

Kawase S, Miyajima S (1971) Multiplication of cytoplasmic polyhedrosis virus. In: Aruga, H., Tanada, Y.(eds). The cytoplasmic polyhedrosis virus of the silkworm. Tokyo, p. 23-59.

Kobayashi M (1971) Cycle of cytoplasmic polyhedrosis virus as observed with the electron microscope. In: Aruga, H., Tanada, Y.(eds). The cytoplasmic polyhedrosis virus of the silkworm. Tokyo, p. 23-59.
Li G, Wu KM, Gould F, Feng H, He Y, Guo Y (2004) Frequency of $B t$ resistance genes in Helicoverpa armigera populations from the Yellow River cotton-farming region of China. Entomol Exp Appl 112:135.

Li Y, Tan L, Chen W, Zhang J, Hu Y (2006) Identification and genome characterization of Heliothis armigera cypovirus types 5 and 14 and Heliothis assulta cypovirus type 14. J Gen Virol 87:87-394.

Martignoni ME, Iwai PJ (1981) A catalogue of viral disease of insects, mites, and ticks. In: Burges, H.D.(ed). Microbial control of pests and plant diseases. academic press, New York, p.897-911.

Marzban R, He Q, Liu XX, Zhang QW (2009) Effects of Bacillus thuringiensis toxin CrylAc and Cytoplasmic polyhedrosis virus of Helicoverpa armigera (Hübner) (HaCPV) on Cotton bollworm (Lepidoptera: Noctuidae). J Invertebr Pathol 101:71-76.

Marzban R (2012) Midgut pH Profile and Energy Differences in Lipid, Protein and Glycogen Metabolism of Bacillus thuringiensis Cry1Ac Toxin and Cypovirus-infected Helicoverpa armigera (Hübner) (Lepidoptera: Noctuidae). J Entomol Res Soc 14:45-53.

Mertens PPC, Pedley S, Crook NE, Rubinstein R, Payne CC (1999) A comparison of the genomic dsRNA segments of six cypovirus isolates by cross-hybridization of their dsRNA genome segments. Arch Virol 144:561-566.

Mertens PPC, Rao S, Zhou H (2004) Cypovirus. In: Fauquet, C.M., Mayo, M.A., Maniloff, J., Desselberger, U., Ball, L.A.(eds). Virus taxonomy: eighth report of the International Committee on Taxonomy of Viruses. Elsevier/Academic Press, London, p. 522-533.

Payne CC, Rivers CF (1976) Aprovisional classification of cytoplasmic polyhedrosis virus based on the size of the RNA genome segments. J Gen Virol 33:71-81.

Shen J, Zhou W, Wu Y, Lin X, Zhu X (1998) Early resistance of Helicoverpa armigera (Hubner) to Bacillus thuringiensis and its relation to the effect of transgenic cotton lines expressing Bt toxin on the insect. Acta Entomol Sin 41:8-14.

Sikorowski PP, Thampson AC (1979) Effects of cytoplasmic polyhedrosis virus on diapausing Heliothis virescens. J Invertebr Pathol 33:66-70.

Wiygul G, Sikorowski PP (1991) Oxygen uptake in larval bollworm (Heliothis zea) infected with iridescent virus. J Invertebr Pathol 58:252-256.

Wiygul G, Sikorowski PP (1978) Oxygen uptake in tobacco budworm larvae(Heliothis virescens) infected with cytoplasmic polyhedrosis virus. J Invertebr Pathol 32:95-191.

Ying SL (1986) A decade of successful control of pine caterpillar, Dendrolimus punctatus walker (lepidoptera: Lasiocampidae), by microbial agents. Forest Ecol Manag 15:69-74.

Zhang H, Zhang J,Yu X,Lu X, Zhang Q, Jakana J, Chen DH, Zhang X, Zhou ZH (1999) Visualization of protein-RNA interactions in cytoplasmic polyhedrosis virus. J Virol 73:1624-1629.

All the content of the journal, except where otherwise noted, is licensed under a Creative Commons License CC BY-NC. 